\title{
Quality assessment of river waters using risk indexes for substances and sites, based on the COMMPS procedure
}

\author{
E. Teixidó, ${ }^{a}$ M. Terrado, ${ }^{b}$ A. Ginebreda ${ }^{c}$ and R. Tauler ${ }^{* c}$ \\ Received 9th April 2010, Accepted 30th July 2010 \\ DOI: $10.1039 / \mathrm{c0em00108b}$
}

The well established risk assessment COMMPS methodology (Fraunhofer Institut, Schmallenberg, Germany) developed at a European basin scale to identify priority pollutants based on their exposure and effects, has been applied at a local scale along a double step process: (a) first, the corresponding adapted list of priority pollutants has been obtained from monitoring data at a regional scale; (b) second, a new site pollution risk index has been developed for the relative comparison of the chemical pollution status of the investigated geographical region. As a case study, representative of the Mediterranean area, the process has been applied to 17 Catalan rivers (NE Spain), using the monitoring data collected between 1997 and 2006 in 207 different sampling sites. After an appropriate selection procedure, 52 parameters were finally used for the calculation of the local priority substance and site risk indexes. From the exposure point of view the most relevant substances at the Catalan scale were volatile organohalogen compounds (VOX) and volatile aromatic hydrocarbons (toluene and xylene), whereas the priority substance risk index points to dibromomethane (volatile organohalogen compound) and benzo-a-anthracene (PAH) as the most concerning compounds. The local and European priority substance indexes have been compared, showing minor differences. Finally, site risk indexes have been calculated and utilized for comparison of the chemical status of different sites. They can be conveniently displayed in quality geographical maps and are considered a valuable tool for the environmental management and risk assessment of the region under study.

\section{Introduction}

Protection of surface freshwater quality and quantity is a matter of paramount importance, not only because it is essential for human life and well-being, but also for the necessity of preservation of the associated aquatic ecosystems (Millenium Ecosystem Assessment 2005). ${ }^{1}$ Understanding that water is far more than a resource has led the European Union to issue the socalled Water Framework Directive (Directive 2000/60/EC). ${ }^{2}$ According to the directive, a good quality status of water bodies

\footnotetext{
'Agència Catalana de l'Aigua, Provença 204-208, 08036 Barcelona, Spain ${ }^{b}$ Catalan Institute for Water Research (ICRA), Emili Grahit 101, Edifici H2O, Parc Científic i Tecnologic de la Universitat de Girona, 17003 Girona, Spain

'Institute of Environmental Assessment and Water Research, Spanish Council of Scientific Research (IDAEA-CSIC), Jordi Girona 18-26, 08034 Barcelona, Spain.E-mail: Roma.Tauler@idaea.csic.es; rtaqam@, cid.csic.es
}

depends on both their ecological and chemical status, and it must be achieved by the EU member states not later than 2015 .

The chemical status of a water body is essentially defined by compliance with the established environmental quality standards (EQS) of a list of 33 compounds: the so-called 'Priority Substances' (PS) and Priority Hazardous Substances (PHS), which have been fixed by the Decision 2455/2001/EC ${ }^{3}$ and further by the Directive 2008/105/EC. ${ }^{4}$ Additionally, eight other pollutants for which EQS already existed in previous legislation, i.e., four cyclodiene pesticides, aldrin, endrin, dieldrin, isodrin, $\mathrm{p}, \mathrm{p}^{\prime}-$ DDT, total DDT (sum of $\mathrm{p}, \mathrm{p}^{\prime}$-DDT, p,o-DDT, DDE and DDD), tetrachloroethylene and trichloroethylene were also included in the list. For all those aforementioned substances, the EU Commission shall submit proposals to control the progressive reduction of discharges, and to phase out emissions of PHS into the environment within the forthcoming 20 years. Concerning the ecological status of surface waters, it is established on the basis of a set of appropriate indices, namely biological,

\section{Environmental impact}

This paper presents the application of the EU risk assessment COMMPS procedure to identify risk priority pollutants based on their exposure and on their toxicological effects. Based on this procedure, and using monitoring data at a local scale, a new site pollution risk index is proposed for the relative comparison of the environmental status of a given geographical area. From the results of the application of these two indexes, the most relevant pollutants in the region under study (considering both their abundance and their toxicological risk) and the ranking of the different sampling sites according to their chemical status were obtained. These results can be conveniently displayed in quality geographical maps which can be considered a valuable tool for the environmental management and assessment of investigated regions. 
hydromorphological and physico-chemical. Within the last category, besides general physico-chemical conditions (thermal, acidity, salinity, oxygenation and nutrients) all other specific pollutants identified as being discharged into the river basin or sub-basin are included, either priority substances or any other pollutant considered relevant. As a whole, all the required information is supported via the data supplied by the corresponding surveillance or operational monitoring programs that are carried out by the responsible water authorities.

The aforementioned list of PS and PHS is the outcome of an extensive risk assessment study carried out by the Fraunhofer Institut (Schmallenberg, Germany), according to the so-called COMMPS (Combined Monitoring-based and Modelling-based Priority Setting Scheme) methodology. ${ }^{5}$ The method has been outlined by D. Lerche et al., ${ }^{6}$ who have compared COMMPS substance ranking results with those obtained using alternative risk assessment methodologies, such as partial order and random linear extensions. Other risk assessment studies related to the release and persistence of chemicals in the environment, mostly in connection with the REACH regulation (Registration, Evaluation, Authorization and Restriction of Chemicals, Regulation (EC) No 1907/2006) ${ }^{7}$ have been carried out, ${ }^{8-10}$ although they are not strictly devoted to the aquatic environment. On the other hand, V. Keller ${ }^{11}$ has examined the suitability of existing hydrological models regarding their ability to predict the fate of chemicals at the catchment scale from a modelling perspective.

As it is evident from its title, the COMMPS procedure aims to quantify the risk associated with the exposure of a given chemical making use of two kinds of data, namely, modelling-based and monitoring-based. It is not the purpose of the present work to discuss the suitability of both types of data, which has been properly addressed elsewhere by A. C. Johnson $e t$ al. ${ }^{12}$ Focusing on the monitoring-base case, data have been retrieved from the respective databases of all the European Member States, thus representing an average of the existing situations in the different involved countries/rivers. Nevertheless, it is obvious that countries, river basins, and even river sections within a catchment can be dramatically heterogeneous due to many reasons (industrial, agricultural and urban pressures, climatic and hydrological changing conditions, etc.).

Taking these facts into consideration, the main aim of the present study is the application of the COMMPS procedure at a smaller (regional) scale, taking as a case study the rivers of Catalonia (NE Spain), which constitute a representative example of Mediterranean conditions. The proposed application enables the comparison of the priority index for organic substances established in the COMMPS at a European scale with the priority index calculated here for the area under consideration. Once the priority index is adapted to the defined study area, a new methodology is proposed to identify where the most polluted sampling sites are ('hot spots'). The obtained indexes range between 0 (worst water quality) and 1 (best water quality), and they are further classified into five descriptive categories. The index is based on a combination of the hazard effects (i.e., toxicity, bioaccumulation and persistence) of a particular pollutant and the average amount of the pollutant detected in a particular sampling site, for a specific time period. Therefore, this index is different to the simple comparison against the established environmental quality standards (EQS) system and provides complementary help for environmental protection policies.

\section{Methods}

\section{Data description}

The database used in this work was obtained from the Catalan Water Agency (ACA) (http://aca-web.gencat.cat/aca/). It consists of the concentrations of a set of organic compounds analyzed after monitoring campaigns carried out from January 1997 to December 2006 in different sampling sites of 17 rivers: 12 small and medium-sized Mediterranean rivers having their origin and end in Catalonia (North-East Spain), 4 interregional basins, composed of the Catalan part of the Ebro River basin and three of its tributaries located in Catalonia (Noguera Pallaresa, Noguera Ribagorçana and Segre rivers), and 1 international river, namely, the Garona River, which has its origin in Catalonia and flows down towards the Atlantic Ocean in France. Table 1 summarizes the river basins and the number of sampling sites and analytical measurements considered in this work for the studied 10-year period (year 1997 to 2006).

\section{Compounds monitored and analytical methods}

Initially, 146 compounds were considered and measured, but only 52 were finally included in the data set for subsequent analysis (see below, the description of requirements for inclusion in the COMMPS procedure). Sampling and extraction procedures, instrumentation, analytical methods and other experimental details including quality assurance parameters have been reported elsewhere. ${ }^{13-18}$

\section{COMMPS procedure outline}

The COMMPS (Combined Monitoring-based and Modellingbased Priority Setting Scheme) $)^{5}$ procedure establishes a ranking of chemical substances according to a risk priority index. In this work, this procedure has been applied to the Catalan river basins

Table 1 Rivers, number of sampling sites and number of analytical measurements

\begin{tabular}{lll}
\hline River basin & \multicolumn{2}{l}{ Number of sampling sitesTotal number of entries } \\
\hline Muga & 10 & 1559 \\
Fluvià & 13 & 1923 \\
Ter & 28 & 5725 \\
Riudaura & 1 & 129 \\
Daró & 1 & 100 \\
Tordera & 16 & 3043 \\
Besòs & 21 & 4815 \\
Llobregat & 48 & 8275 \\
Foix & 6 & 906 \\
Gaià & 3 & 308 \\
Francolí & 8 & 1662 \\
Riudecanyes & 2 & 173 \\
Segre & 23 & 3564 \\
Noguera Ribagorçana4 & 3 & 364 \\
Noguera Pallaresa & 4 & 339 \\
Ebro & 17 & 5413 \\
Garona & 2 & 315 \\
Total sum & 207 & 38613 \\
\hline
\end{tabular}


database (described above) and it is compared with the results obtained for other European river basins. A total of 146 individual compounds were initially considered and compiled from the priority lists of the Member States databases. ${ }^{5}$ However, several criteria should be met for these compounds to be included in the COMMPS procedure for the risk index calculation according to their relevance and representativeness. In this study, these criteria were similarly applied and adapted as described in the COMMPS procedure:

(a) Any substance must be positively monitored in at least 5 instances.

(b) The substance was excluded if the total amount of positive findings (values above the detection limit) was below $10 \%$. However, the substances with less than $10 \%$ of findings were included and reported when positive findings were detected in at least two different river basins.

(c) Sampling sites with different detection limits were eliminated.

(d) All values below the detection limit $(<\mathrm{DL})$ were replaced by half the value of the detection limit $(0.5 \times \mathrm{DL})$, since this has been shown to be the most appropriate procedure if no additional information is available. ${ }^{19}$

Finally, a total number of 52 substances fulfilled the previously described selection criteria. These compounds are listed in Table 2, grouped according to the different families they belong to.

Calculation of the COMMPS substance risk priority index. The risk priority index for a particular substance $\mathrm{i}$ is obtained as the product of a substance's exposure index I_exp, and its corresponding effect index I_eff:

$$
\text { I_prio }{ }_{i}=\text { I_exp }{ }_{i}^{*} I_{-} \text {eff } \text {. }_{\text {. }}
$$

The exposure index of a chemical substance i, I_exp , is calculated using all measured concentration values for the considered substance in every sampling site. In this calculation, only the concentration value corresponding to the 90th percentile, $\mathrm{C}_{\mathrm{i}}$, of all the values measured at every location is taken into account for the calculation according to the expression:

$$
I_{\_} \exp _{\mathrm{i}}=\frac{\log \left(\mathrm{C}_{\mathrm{i}} /\left(0.1 * \mathrm{C}_{\min }\right)\right)}{\log \left(\mathrm{C}_{\max } /\left(0.1 * \mathrm{C}_{\min }\right)\right)} * 10
$$

where $C_{i}$ is the 90 th percentile value calculated from the arithmetic mean values of the concentrations of chemical compound $i$ in every sampling site. Mean values at every site for a particular substance $\mathrm{i}$ are ranked according to their magnitude, and the corresponding 90th percentile concentration value is chosen for each substance as $C_{i} \cdot C_{\min }$ and $C_{\max }$ are defined respectively as the minimum and maximum concentration values known to be found for organic substances in the water phase, $C_{\max }$ was set to $100 \mu \mathrm{g}$ $\mathrm{L}^{-1}$ and $\mathrm{C}_{\min }$ was set to $0.0001 \mu \mathrm{g} 1^{-1}$ for all substances. ${ }^{5}$ These values have been adopted in the COMMPS procedure since they are close to the maximum and minimum levels of the 90 percentile of the concentration of the different substances in the existing database for the EU member states. The product of the lower limit $\left(\mathrm{C}_{\mathrm{min}}\right)$ by a factor of 0.1 is introduced to avoid zero logarithm values in eqn (2) calculations when $C_{i}$ is equal to $C_{\text {min }}$.

For the effect index of a chemical substance i, I_eff $f_{i}$ calculation, direct and indirect effects on aquatic organisms are considered (toxicity and potential bioaccumulation) as well as indirect effects on humans via ingestion of contaminated water or food (carcinogenicity, mutagenicity and adverse effects on reproduction as well as chronic effects resulting from oral uptake). All these data were taken from the COMMPS procedure annex, ${ }^{5}$ except for the case of two compounds (ethion and chrysene), which were calculated as indicated below according to the COMMPS procedure. The effect index I_eff $f_{i}$ is then obtained as the sum of three effect parameters relative to the considered substance: $\mathrm{EFS}_{\mathrm{d}}$ for direct effects of the considered substance on aquatic organisms, $\mathrm{EFS}_{\mathrm{i}}$ for indirect effects of the considered substance on aquatic organisms, and $\mathrm{EFS}_{\mathrm{h}}$ for indirect effects of the considered substance on humans (subindex i for the considered substance $i$ is omitted for these three parameters to make them more readable):

$$
\text { I_eff }{ }_{\mathrm{i}}=\mathrm{EFS}_{\mathrm{d}}+\mathrm{EFS}_{\mathrm{i}}+\mathrm{EFS}_{\mathrm{h}} \text {. }
$$

The scores for the direct effect in aquatic organisms, $\mathrm{EFS}_{\mathrm{d}}$ (see TGD, Technical Guidance Documents ${ }^{20}$ ), were calculated based on the compiled PNEC (Predicted Non-Effect Concentration) values according to the equation:

$$
\mathrm{EFS}_{\mathrm{d}}=5 * \frac{\log \left(\mathrm{PNEC} /\left(10 * \mathrm{PNEC}_{\text {max }}\right)\right)}{\log \left(\mathrm{PNEC}_{\min } /\left(10 * \mathrm{PNEC}_{\max }\right)\right)}
$$

where, $\mathrm{PNEC}_{\min }$ values were set to $0.000001 \mathrm{mg} \mathrm{1^{-1 }}$ and

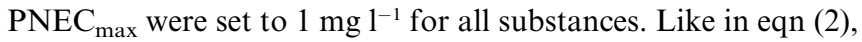
the product of $\mathrm{PNEC}_{\max }$ by a factor of 10 is performed to avoid $\log$ zero calculations. The value of PNEC was extrapolated from chronic or acute contamination data according to the method laid down in the TGD documentation. ${ }^{20}$ The selected concentration value was then divided by an assessment factor (AF) which depends on the size of the data ensemble, the test duration and the tested trophic levels. In the case that no effect data were available, $10 \mathrm{ng} \mathrm{l}^{-1}$ was used as default value for PNEC. If both, acute and chronic data, were available, the chronic data was normally preferred for the calculation of PNEC.

The factor of 5 introduced in eqn (4) refers to the so-called weighting factor for direct effects (equal to 5 for organic substances and to 8 for metals).

For both chrysene and ethion compounds, LC50 (lethal concentration for $50 \%$ of the individuals in the group) was used to calculate PNEC values (LC50 from HSDB, Hazardous Substances Data Bank). Therefore, for both compounds an assessment factor (AF) of 1000 has been used (see COMMPS procedure ref. 5).

The indirect aquatic effect scores, $\mathrm{EFS}_{\mathrm{i}}$, measure the potential bioaccumulation, and were calculated from the bioconcentration factor $(\mathrm{BCF})$, or alternatively, from the $\log \mathrm{P}_{\mathrm{ow}}$ (octanol-water partition coefficient). For chrysene and ethion, $\log \mathrm{P}_{\mathrm{ow}}$ was used to calculate $\mathrm{EFS}_{\mathrm{i}}$ (data from SRC, Syracuse Research Corporation). For both compounds, $\log \mathrm{P}_{\text {ow }}$ is above 5, thus $\mathrm{EFS}_{\mathrm{i}}$ scores are equal to 3 (see COMMPS procedure ref. 5).

The scores for the effects on humans, $\mathrm{EFS}_{\mathrm{h}}$, were established using the official R-phrases (ECB European Chemicals Bureau IUCLID database) used in the labeling of chemical substances, which are considered to be a measure of the carcinogenicity, mutagenicity, effects on reproduction and chronic effects of substances. R-phrases and assigned scores are described in 


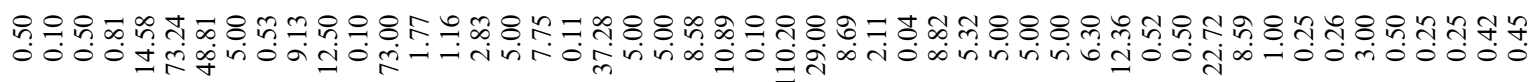

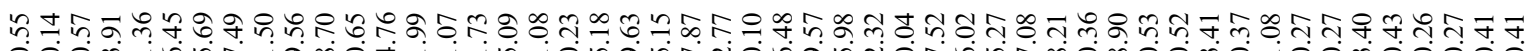

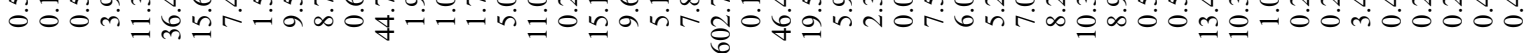

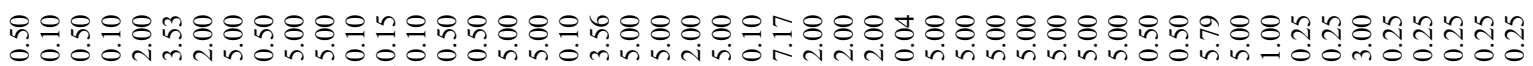

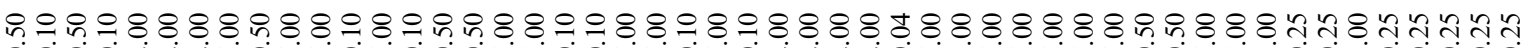

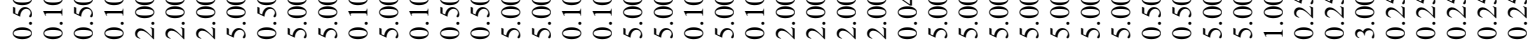

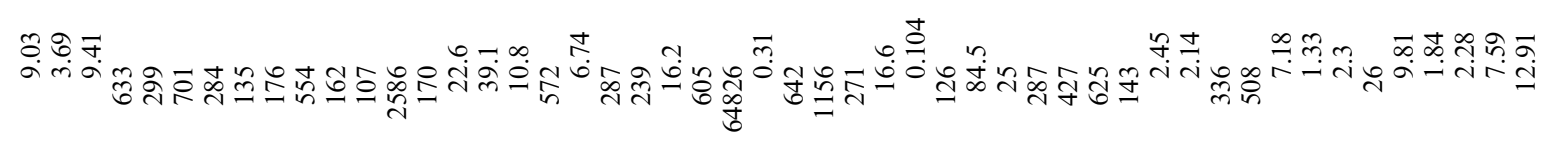

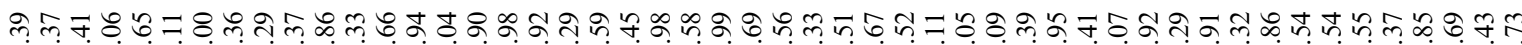

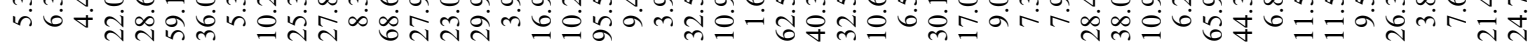
(1) 
COMMPS procedure ref. 5. For chrysene, a score of $\mathrm{EFS}_{\mathrm{h}}$ of 2 has been assigned because of its carcinogenicity toxicity (R-45). Ethion has no human effects reported, and it has an $\mathrm{EFS}_{\mathrm{h}}$ score of zero (R-phrases of ECB European Chemicals Bureau IUCLID database).

The total effect index for the considered organic compounds was finally calculated as the sum of the 3 aforementioned parameters, according to eqn (3). The relative weights associated to these parameters for the index calculation have been established by experts, based in the COMMPS report. Weights were $5: 3: 2$ for $\mathrm{EFS}_{\mathrm{d}}: \mathrm{EFS}_{\mathrm{i}}: \mathrm{EFS}_{\mathrm{h}}$. Finally, for chrysene the effect index is 7.69 and for ethion the effect index is 7.82 .

Computation of the site pollution risk index. A new procedure is proposed in this work to compute a site pollution risk index based in the COMMPS procedure. It uses similar criteria to evaluate the potential risk of different substances present in a specific sampling site and, subsequently, takes all these substances into account to calculate a new score for the priority index, this time characteristic for each particular site. The selection criteria to define the organic compounds to be included in the calculation of the site pollution risk index was the percentage of positive values (above detection limit) encountered. Substances were excluded if the total number of positive findings of mean values was less than $15 \%$. In this way, 25 compounds were finally selected to be included in the evaluation of the site pollution risk index, corresponding to those found in the highest number of sampling sites. Selected compounds used to calculate the site pollution risk index are marked with an asterisk in Table 2.

The site pollution risk index was calculated as the product of the exposure index and the corresponding effect index of all the substances detected in each sampling site according to the following equation:

$$
I_{\text {_site }}=\frac{\sum_{\mathrm{i}=1}^{\mathrm{n}} \mathrm{I} \_ \text {exp }_{\mathrm{ij}} \mathrm{I}_{-} \text {eff }}{\mathrm{i}}
$$

Where I_site $\mathrm{j}_{\mathrm{j}}$ is the site pollution risk index assigned to site $\mathrm{j}$, I_exp $\mathrm{e}_{\mathrm{ij}}$ the exposure index of substance $\mathrm{i}$ in sampling site $\mathrm{j}$, and I_eff $f_{i}$ the effect index (direct and indirect effects) of substance $i ; n$ being the number of substances (organic compounds) included in the calculation. The exposure index of each compound i, I_exp $p_{i j}$, at each sampling site $\mathrm{j}$ is calculated as follows:

$$
I_{-} \exp _{\mathrm{ij}}=10\left(\frac{\log \left(\frac{\mathrm{Cmean}_{\mathrm{ij}}}{0.1 \mathrm{Cmin}}\right)}{\log \left(\frac{\mathrm{Cmax}}{0.1 \mathrm{Cmin}}\right)}\right)
$$

Where $\mathrm{Cmean}_{\mathrm{ij}}$ is the arithmetic mean of the $\mathrm{i}$ substance concentrations in sampling site $\mathrm{j} . \mathrm{Cmin}_{\mathrm{i}}$ and $\mathrm{Cmax}_{\mathrm{i}}$ are defined, as before, as the minimum and maximum concentrations of compound $\mathrm{i}$ in the water phase. The finally selected values for all compounds were $\mathrm{Cmax}=100 \mu \mathrm{g} \mathrm{L}^{-1}$ and $\mathrm{Cmin}=0.0001 \mu \mathrm{g}^{-1}$ (see before the calculation of the exposure index I_exp). The calculation of I_eff $f_{i}$ was also performed as described for the risk priority index calculation for each organic compound. Once all I_site ${ }_{j}$ were obtained, their values were properly normalized according to the following equation:

$$
\text { I_sitenorm }=\frac{\left(I_{j} \_ \text {site }_{\mathrm{j}}-\mathrm{I} \_\min _{\mathrm{j}}\right)}{\left(\mathrm{I} \_\mathrm{max}_{\mathrm{j}}-\mathrm{I} \_\min _{\mathrm{j}}\right)}
$$

Where I_sitenorm $\mathrm{j}_{\mathrm{j}}$ is the normalized risk priority index for sampling site j. I_site ${ }_{j}$ is calculated according to eqn (5). I_min ${ }_{j}$ is the lowest value of the index and I_max $\operatorname{man}_{\mathbf{j}}$ the highest value calculated by eqn (5). For unpolluted sites, I_min ${ }_{j}$ should ideally correspond to blank samples. Finally, a mapping approach was used to represent the site pollution risk index over the geographical area under study.

\section{Results and discussion}

\section{Priority and exposure risk indexes}

The behavior of the different investigated compounds can be observed in Fig. 1 regarding their calculated exposure and effect index values, which were finally combined into a characteristic priority index. In general, the exposure indexes, I_exp $p_{i}$, found in Catalonia region were slightly below those reported at a European level (Fig. 1). Families that showed higher exposure indexes were volatile organohalogen compounds (VOX) and volatile aromatic hydrocarbons (toluene and xylene), thus indicating their occurrence in a higher number of locations and at higher concentrations. For these compounds, the exposure index exceeded the average value (4.4) in all the cases considered in this work.

Regarding the effect index, I_eff, which gives an indication of the danger of a particular chemical compound for humans and aquatic organisms, taking into consideration its persistence, toxicity and bioaccumulation capacity, the highest values corresponded to polycyclic aromatic hydrocarbons (PAHs) (particularly benzo- $a$-anthracene and acenaphthylene), and to some persistent organochlorine compounds like pentachlorophenol, DDT (and its degradation products DDE and DDD), hexachlorocyclohexanes and hexachlorobenzene. It is important to highlight that in the case of these compounds, the highest levels obtained for the effect index coincided with rather low levels in their exposure. Although, these are well known hazardous substances threatening human and aquatic life, they are fortunately usually detected at low concentrations in the investigated environments. This fact attenuates their pernicious environmental impact, thus reflecting the positive effects of the regulatory enforcement efforts deployed since the 1970s. Triazines, volatile organic compounds and volatile aromatic hydrocarbons (toluene and xylene) are substances that have lower effect indexes, I_eff, and they were found below the average value (5.6) in almost all cases.

Substances with a higher priority index, I_prio ${ }_{i}$, were dibromochloromethane (VOX) and benzo- $a$-anthracene (PAH). Dibromochloromethane presented average values for the exposure and effect indexes of 6.3 and 6.1, respectively, while benzo- $a$ anthracene behaved totally differently, presenting the highest effect index of the list (9.3), but having, at the same time, a rather low exposure index (3.9). Even though this last compound was top ranked in the list according to the local priority index I_prio its presence in the environment in the area of Catalonia can be qualified as rather low. 


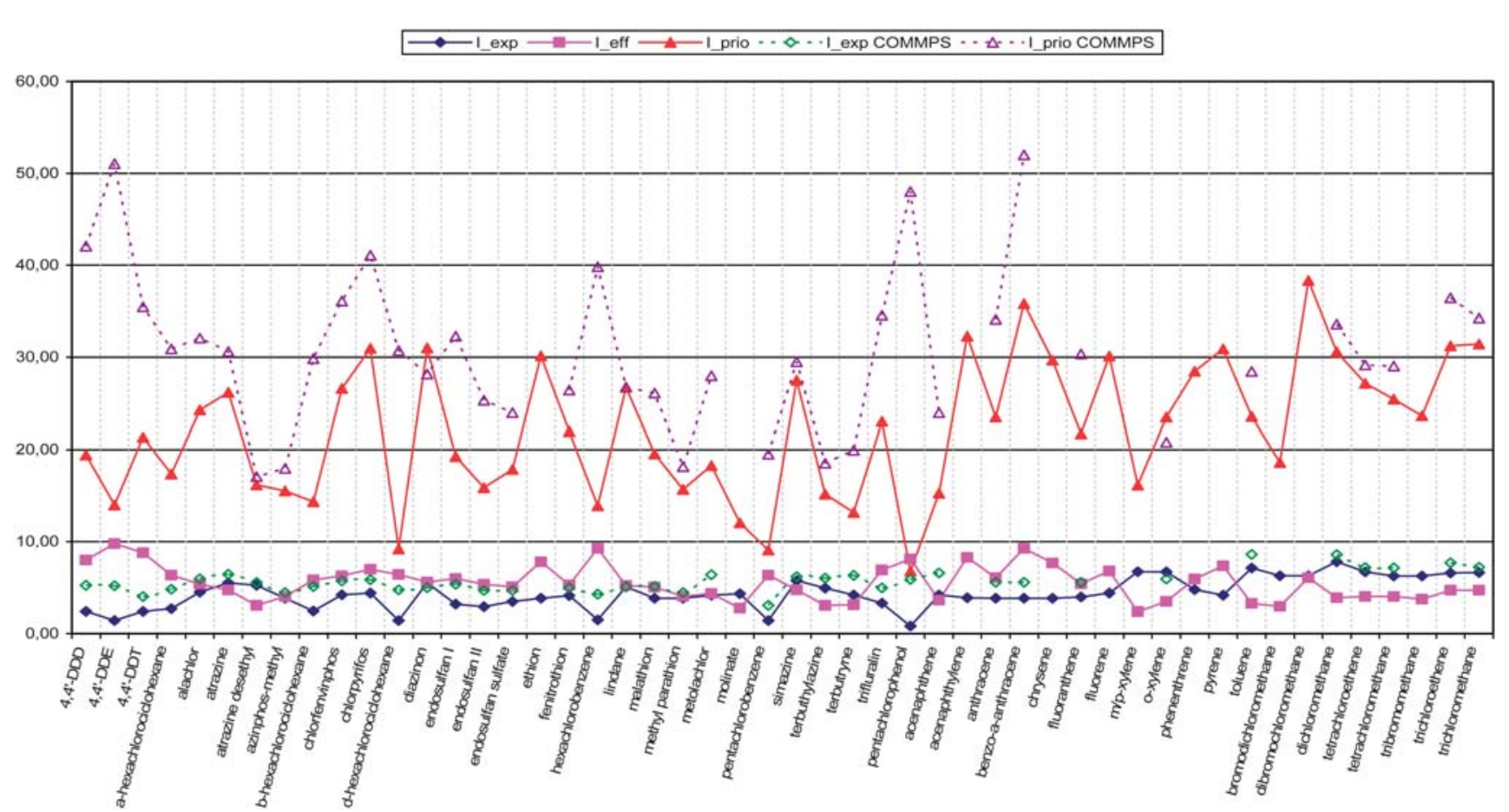

Fig. 1 Results of the priority index and the exposure index calculated using the COMMPS procedure (I_prio COMMPS and I_exp COMMPS) and compared with the three indexes calculated in this study: the exposure index (I_exp), the effect index (I_eff) and the priority index (I_prio) for the investigated organic compounds.

Other compounds showing relatively high priority index values were acenaphthylene (PAH), trichloromethane and trichloroethane (VOXs), and diazinon (organophosphate pesticide). Pentachlorophenol has a rather high effect index but a very low exposure index in the area under study (the majority of measures are found to be under their analytical detection limit), which minimizes the actual risk associated to this particular substance.

The comparison of the priority index in the area under study with the priority index of COMMPS ${ }^{5}$ is also displayed in Fig. 1. The priority and effect indexes obtained by both studies did not differ much. The priority index of DDT families, hexachlorobenzene, endosulfan I, benzo- $a$-anthracene and pentachlorophenol in COMMPS are higher than in the present study. Moreover, it is worth noting that in the present work, some compounds were not included in the original COMMPS study, ${ }^{5}$ thus it is not possible to carry out a direct comparison.

A sensibility analysis for the substance risk priority index was carried out. Two test values of the $\mathrm{C}_{\mathrm{i}}$ (90th percentile of the arithmetic mean concentration values of every substance) were applied to eqn (2). The first test value was attained by doubling (two times) $\mathrm{C}_{\mathrm{i}}$ values and the second test value was achieved by halving (dividing by 2) $\mathrm{C}_{\mathrm{i}}$ values. A new I_exp $\mathrm{p}_{\mathrm{i}}$ was then recalculated for each chemical compound and sampling site. Also a new I_prio ${ }_{i}$ was calculated according to eqn (1). Chemical compounds with higher effect index (I_eff) were more affected by changes in $C_{i}$ because of the multiplication of the two indexes (I_eff and I_exp, see eqn (1)). These compounds were DDT (and its degradation products DDE and DDD), hexachlorobenzene, pentachlorophenol, ethion and some aromatic hydrocarbons (benzo- $a$-anthracene, crysene, pyrene and acenaphthylene). Nevertheless, since these compounds had an exposition index below the mean, their uncertainty results were very low and the recalculated results showed little difference with those obtained previously from COMMPs.

\section{Site pollution risk index}

Site pollution risk indexes calculated according to eqn (5) were obtained for the 207 concerned sampling sites. The number of samples used to calculate the site pollution risk indexes is summarized in Table 3 , and the distribution of the site pollution risk index over the territory of Catalonia is displayed in Fig. 2. Index values were normalized and divided into 5 different categories for representation purposes, and ranked according to the different level of pollution in surface water. Categories were comprised between 0 (lower level of pollution) and 1 (upper level of pollution) and they were displayed in different colours in the map.

Results showed clearly that the northern areas in the Catalan territory, which correspond to the mountainous areas (Pyrenees) where river sources are located, usually present low values for this pollution index (sites displayed in blue and green in Fig. 2). These results were already expected since they corresponded to the more pristine areas with lower anthropogenic pressures, and therefore sites that are less exposed to chemical pollution.

Conversely, relatively high levels on the site pollution risk index were detected for locations in the Segre River basin (the main tributary of the Ebro River), in the plains surrounding the city of Lleida. This pollution can be attributed to important agricultural activities which are developed in the region nearby. This type of pollution is also identified in the Ebro River main axis, whose waters flow through important agricultural zones before entering into the Catalan region. Importantly, high levels 

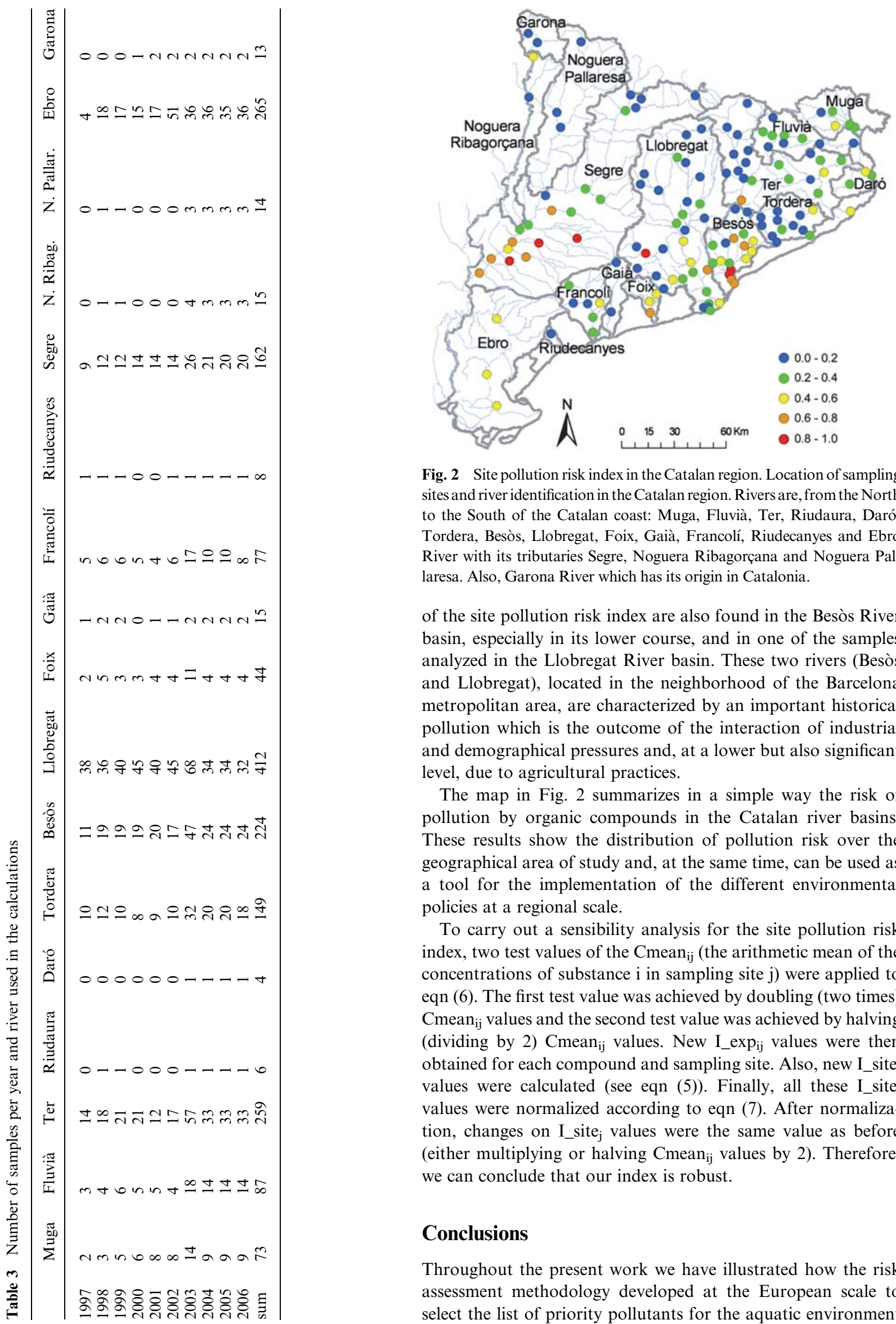

Fig. 2 Site pollution risk index in the Catalan region. Location of sampling sites and river identification in the Catalan region. Rivers are, from the North to the South of the Catalan coast: Muga, Fluvià, Ter, Riudaura, Daró, Tordera, Besòs, Llobregat, Foix, Gaià, Francolí, Riudecanyes and Ebro River with its tributaries Segre, Noguera Ribagorçana and Noguera Pallaresa. Also, Garona River which has its origin in Catalonia.

of the site pollution risk index are also found in the Besòs River basin, especially in its lower course, and in one of the samples analyzed in the Llobregat River basin. These two rivers (Besòs and Llobregat), located in the neighborhood of the Barcelona metropolitan area, are characterized by an important historical pollution which is the outcome of the interaction of industrial and demographical pressures and, at a lower but also significant level, due to agricultural practices.

The map in Fig. 2 summarizes in a simple way the risk of pollution by organic compounds in the Catalan river basins. These results show the distribution of pollution risk over the geographical area of study and, at the same time, can be used as a tool for the implementation of the different environmental policies at a regional scale.

To carry out a sensibility analysis for the site pollution risk index, two test values of the $\mathrm{Cmean}_{\mathrm{ij}}$ (the arithmetic mean of the concentrations of substance $i$ in sampling site $j$ ) were applied to eqn (6). The first test value was achieved by doubling (two times)

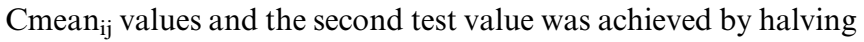
(dividing by 2) Cmean $_{\mathrm{ij}}$ values. New I_exp $\mathrm{ij}_{\mathrm{ij}}$ values were then obtained for each compound and sampling site. Also, new I_site values were calculated (see eqn (5)). Finally, all these I_site values were normalized according to eqn (7). After normalization, changes on I_site j values were the same value as before (either multiplying or halving $\mathrm{Cmean}_{\mathrm{ij}}$ values by 2 ). Therefore, we can conclude that our index is robust.

\section{Conclusions}

Throughout the present work we have illustrated how the risk assessment methodology developed at the European scale to select the list of priority pollutants for the aquatic environment 
(COMMPS procedure), can also be advantageously used at a regional scale, using Catalan rivers as a representative example. Two main conclusions have been derived. First, the procedure has allowed the identification of the most relevant pollutants in the region under study, including local exposure data, and consequently, has allowed the adaptation of the COMMPS index to local and regional characteristics. Secondly, by aggregation of the priority substance index, a site pollution specific risk index has been proposed to compare, on relative terms, the chemical pollution status of different sites at a regional scale, in this case, along the rivers of Catalonia. The use of the proposed site pollution specific risk index allows for fast visualization and a comparison of the more environmentally stressed river location areas. Nonetheless, the proposed index can be easily expanded in the future for the inclusion of more compounds.

A further and obvious added value of the proposed COMMPS-based local pollution index is its use for water management purposes and risk assessment, since it can be easily used to monitor the chemical quality of water bodies on geographical and regional maps. In this way, the index can be envisaged as a valuable tool to be used, by responsible water authorities, to follow the WFD implementation and to optimize the design of adequate surveillance and operational monitoring campaigns and better allocate the always limited resources. Therefore, the methods proposed in this paper constitute an effort to provide useful tools for the current implementation of the River Basin Management Plans (RBMP) and the related programs of measures within the context of the WFD.

\section{Acknowledgements}

We are grateful to the Catalan Water Agency (Agència Catalana de l'Aigua, ACA) for allowing access to monitoring data and to Ministerio de Ciencia e Inovación, Spain, for the CTQ200911572 research grant.

\section{References}

1 Millennium Ecosystem Assessment. 2005. Ecosystems and Human Well-being: Synthesis. Island Press, Washington, DC. p. 137.

2 Directive 2000/60/EC of the European Parliament and of the Council of 23 October 2000 establishing a framework for Community action in the field of water policy, Official Journal of the European Communities, L327, 22.12.2000.

3 Decision 2455/2001/EC of the European Parliament and of the Council of 20 November 2001 approving the list of priority substances in the field of water policy, Official Journal of the European Communities, L331, 15.12.2001.

4 Directive 2008/105/EC of the European Parliament and of the Council of 16 December 2008 on environmental quality standards in the field of water policy, amending and subsequently repealing Council Directives 82/176/EEC, 83/513/EEC, 84/156/EEC, 84/491/EEC, 86/ 280/EEC and amending Directive 2000/60/EC of the European Parliament and of the Council. Official Journal of the European Union, L348, 24.12.2008.
5 CEC 1999. Revised Proposal for a List of Priority Substances in the Context of the Water Framework Directive (COMMPS Procedure). Fraunhofer-Institut Umweltchemie und Ökotoxicologie. 98/788/3040/ $\mathrm{DEB} / \mathrm{E} 1$

6 D. Lerche, P. B. Sorensen, H. S. Larsen, L. Carlsen and O. J. Nielsen, Comparison of the combined monitoring-based and modelling-based priority setting scheme, with partial order theory and random linear extensions for ranking of chemical substances, Chemosphere, 2002, 49, 637-649.

7 Regulation (EC) No 1907/2006 of the European Parliament and of the Council of 18 December 2006 concerning the Registration, Evaluation, Authorisation and Restriction of Chemicals (REACH), establishing a European Chemicals Agency, amending Directive 1999/45/EC and repealing Council Regulation (EEC) No 793/93 and Commission Regulation (EC) No $1488 / 94$ as well as Council Directive 76/769/EEC and Commission Directives 91/155/EEC, 93/ 67/EEC, 93/105/EC and 2000/21/EC. Official Journal of the European Union, L396, 30.12.2006).

8 T. Vermeire, M. Rikken, L. Attias, P. Boccardi, G. Boeije, D. Brooke, J. De Bruijn, M. Comber, B. Dolan, S. Fischer, G. Heinemeyer, V. Koch, J. Lizjen, B. Müller, R. Murray-Smith and J. Tadeo, European Union system for the evaluation of substances: the second version, Chemosphere, 2005, 59, 473-485.

9 K. Kawamoto and K. A. Park, Calculation of environmental concentration and comparison of output for existing chemicals using regional multimedia modelling, Chemosphere, 2006, 63, 11541164 .

10 F. A. M. Verdonck, P. A. Van Sprang and P. A. Vanrolleghem, An intelligent data collection tool for chemical safety/risk assessment, Chemosphere, 2008, 70, 1818-1826.

11 V. Keller, Risk assessment of "down-the-drain" chemicals: search for a suitable model, Sci. Total Environ., 2006, 360, 305-318.

12 A. C. Johnson, T. Ternes, R. J. Williams and J. P. Sumpter, Assessing the concentrations of Polar Organic Microcontaminants from Point Sources in the Aquatic Environment: Measure or Model?, Environ. Sci. Technol., 2008, 42(15), 5390-5399.

13 Council Directive 98/83/EC of 3 November 1998 on the quality of water intended for human consumption. (Official Journal of the European Union L 330, 5.12.1998).

14 Council Directive 2009/90/EC of 31 July 2009 laying down, pursuant to Directive 2000/60/EC of the European Parliament and of the Council, technical specifications for chemical analysis and monitoring of water status (Official Journal of the European Union, L201, 1.8.2009).

15 U.S. Environmental Protection Agency Method 625, Guidelines Establishing Test Procedures for the Analysis of Pollutants under the Clean Water Act: Final Rule and Intern Final Rule and Proposed Rule, 1984.

16 Determination of organic compounds in drinking water by liquidsolid extraction and capillary column gas chromatography/mass spectrometry. Revision 2.2, EPA Method 525.1. Vol. 56, p. 30272 (July 17, 1991).

17 U.S. Environmental Protection Agency. 1984. Method 624Purgeables. 40 CFR Part 136, p. 43373; Federal Register 49, No. 209.

18 U.S. Environmental Protection Agency. 1989. Method 503.1Revision 2.0. Volatile aromatic and unsaturated organic compounds in water by purge and trap gas chromatography. T. A. Bellar.

19 I. M. Farnham, A. K. Singh, K. J. Stetzenbach and K. H. Johannesson, Treatment of non-detects in multivariate analysis of groundwater geochemistry data, Chemom. Intell. Lab. Syst., 2002, 60, 265-281.

20 TGD Technical guidance documents in support of the Commission Directive/67/ECC on risk assessment for new notified substances and the Commission Regulation 1488/94 on risk assessment for existing substances. 